\title{
Frequentar a Etnografia: um passeio etnográfico pela formação em Ciências Sociais $\sqrt{ }$
}

Felipe Figueiredo ${ }^{1}$

\section{Resumo}

Neste artigo elaboro algumas reflexões acerca de minha trajetória enquanto estudante de ciências sociais na Universidade Federal de São Paulo e na importância que a pesquisa etnográfica teve nela. Trata-se, portanto, de uma etnografia de uma trajetória acadêmica em ciências sociais. O objetivo central do artigo é apresentar uma crítica à separação de ensino e pesquisa, refletindo qual o lugar do ensino na pesquisa e da pesquisa no ensino. Por fim, elaboro algumas ideias acerca do ensino e pesquisa durante a pandemia do Covid-19.

Palavras-chave: Ensino - Pesquisa - Etnografia - Ciências Sociais

\begin{abstract}
In this article, I reflect my academic trajectory as a social sciences' undergraduate degree student at the Federal University of São Paulo, and the importance of the ethnographic field work on it. Therefore, it is a academic trajectory etnography in social sciences. The main objective of this article is to present a critic point of view to the dichotomy between teaching and researching, reflecting teaching's place in researching and researching's place in teaching. At the end, I desenvolve some ideas about teaching and researching during the Covid-19 pandemia.
\end{abstract}

Keywords: Teaching- Researching - Ethnography - Social Sciences.

\footnotetext{
${ }^{1}$ Mestrando em Ciências Sociais pela Universidade Federal de São Paulo e membro do Grupo de Pesquisas Visuais e Urbanas (VISURB). E-mail: felipe.figueiredo@unifesp.br
} 
Uma educação pela pedra: por lições; para aprender da pedra, frequentá-la; captar sua voz inenfática, impessoal (pela de dicção ela começa as aulas). A lição de moral, sua resistência fria ao que flui e a fluir, a ser maleada; a de poética, sua carnadura concreta; a de economia, seu adensar-se compacta: lições da pedra (de fora para dentro, cartilha muda), para quem soletrá-la.

Outra educação pela pedra: no Sertão (de dentro para fora, e pré-didática). No Sertão a pedra não sabe lecionar, e se lecionasse, não ensinaria nada; lá não se aprende a pedra: lá a pedra, uma pedra de nascença, entranha a alma. João Cabral de Melo Neto

\section{Introdução}

Este artigo foi escrito como parte da avaliação para a disciplina de Etnografias e Teorias Etnográficas do PPGCS, ministrada pelo Prof. Dr. Alexandre Barbosa Pereira, na UNIFESP, Campus Guarulhos, no segundo semestre de 2019. Além das discussões realizadas em sala de aula, este artigo tem como norte teórico metodológico a etnografia realizada ao longo de uma pesquisa de iniciação científica, entre 2017 e 2018, ressaltando uma especificidade deste trabalho de campo: o fato de ser a primeira etnografia realizada pelo autor durante a graduação. Essa peculiaridade do trabalho de campo escolhido como referência para o presente estudo é fundamental para o principal objetivo do presente texto, que é discutir de maneira crítica a relevância que a etnografia tem na formação de novos pesquisadores, assim como as aulas que o estudante de ciências sociais cursa ao longo de sua formação. Estão esboçadas abaixo algumas potencialidades dessa abordagem teórico-metodológica enquanto forma pedagógica de pesquisa e de aprendizagem na própria disciplina.

Abordamos, portanto, ao longo do artigo, como essa etnografia em específico teve papel na formação do pesquisador em questão e pôde ser uma porta de entrada ao 
mundo da pesquisa, sendo a escrita etnográfica uma ferramenta possível de realização criativa do trabalho científico. Quais especificidades a realização de uma etnografia coloca para os pesquisadores em formação, e como esta pode ser apropriada de forma criativa, mas também pedagógica ao próprio pesquisador em sua formação enquanto etnógrafo? Em suma, ao compartilhar essa primeira experiência etnográfica, procuro sistematizar e compartilhar em forma de texto algumas questões que foram fundamentais para minha formação como pesquisador, que creio serem pertinentes àquelas e àqueles que estejam começando no mundo da etnografia e da pesquisa científica em ciências sociais de maneira mais ampla.

A ideia, portanto, é que o artigo se desenhe como um passeio pela experiência etnográfica, não um manual de como realizá-la. Mais que isso, o texto pode ser lido também como uma pequena etnografia da trajetória de um jovem pesquisador, visando também algumas reflexões que foram levantadas nas discussões ao longo da disciplina acerca do ensino de Ciências Sociais no Brasil. Assim, não caímos na armadilha de realizar um "balanço geral" ou sistematizado do ensino de Antropologia e Ciências Sociais que, como comenta Lévi-Strauss, estaria fadado a ser colocado de forma arbitrária, deformado e perdido em relatos históricos muito particulares para cada país ou mesmo para cada universidade (Lévi-Strauss, 2012). A exposição a seguir parte, portanto, da exposição de uma situação real e localizada (do ensino de ciências sociais na Universidade Federal de São Paulo) $)^{2}$.

\section{Minha primeira etnografia}

A etnografia em questão aconteceu em Macaúbas, município no Sul da Bahia, em 2018, nos meses de Janeiro e Julho, meses de férias universitárias, o que me possibilitou ir a campo sem que eu perdesse as aulas na graduação. Além disso, contou com um "précampo” em 2017, que consistiu em uma visita ao município para entrar em contato com

\footnotetext{
2 Acerca dos usos dos termos "Antropologia" e "Ciências Sociais" ao longo do texto, portanto, não há uma separação rigorosa entre as duas, tendo em vista que o ensino da antropologia, como é o caso na Unifesp (e em muitas universidades brasileiras) é realizado dentro do departamento de Ciências Sociais. Optamos por usar ambos no texto apenas para acentuar o caráter teórico-metodológico adotado de maneira mais comum por uma abordagem antropológica dentro das Ciências Sociais, pela predileção do uso do trabalho de campo etnográfico. Acerca da inserção da Antropologia nas Ciências Sociais, consultar "LÉVI-STRAUSS, 2012".
} 
alguns dos interlocutores, e que foi fundamental para a escrita do projeto de pesquisa que posteriormente foi aprovado e financiado pela FAPESP (2017/10131-6). Esse ponto também é fundamental, pois com os recursos de pesquisa eu consegui não só me manter, mas também realizar as viagens de campo. De antemão, há dois obstáculos no Brasil hoje para a realização do trabalho etnográfico durante a graduação (sem levar em consideração ainda a pandemia do coronavírus): falta de tempo e de recurso.

O assunto principal da pesquisa era uma poesia oral, criada por volta de 1930 durante a construção de um açude na cidade pelo então Instituto Federal de Obras Contra a Seca (Figueiredo, 2018). Essa poesia em forma de ABC nos conta, na voz dos operários, as condições de exploração de sua força de trabalho ao longo da construção da barragem. Foi buscando essa memória que me encontrei com Bio, Beata, Preta, Estevão e França, meus interlocutores de pesquisa. Cabe dizer ainda que este último é meu avô e, portanto, não se tratava de um lugar totalmente estranho, o que facilitou sua realização e entrar em contato com outras pessoas fundamentais para o conhecimento de tal poesia e histórias relativas a ela. Além disso, as condições materiais de realização da pesquisa como hospedagem, alimentação e locomoção foram muito facilitadas devido a essa familiaridade. A poesia veio até mim por relatos de familiares, e que considero como sendo um verdadeiro achado antropológico devido a seu caráter poético que além de contribuir para o patrimônio das poesias orais do sertão nordestino também é um dado histórico fundamental como memória de muitas obras contra a seca construídas na região do semiárido brasileiro.

Além disso, um acontecimento que me levou a pesquisar a relação entre políticas de gestão da natureza e memória foi a participação no Grupo de Pesquisas Visuais e Urbanas da Unifesp (VISURB), grupo coordenado pela professora Andréa Barbosa, ativo desde $2007^{3}$. Na mesma época em que conheci a poesia do ABC do Açude, nós do VISURB realizávamos uma pesquisa acerca dos rios de São Paulo, abordando a relação entre Natureza e Cultura na antropologia. Portanto, foram essas pequenas coincidências em minha história de vida que me levaram a realizar tal etnografia, o que nos leva ao tema da subjetividade e objetividade do conhecimento na pesquisa antropológica e nas ciências sociais que abordaremos mais adiante.

\footnotetext{
${ }^{3}$ https://visurb-unifesp.wixsite.com/visurb-unifesp
} 
Pois bem, depois de conseguir os contatos com alguns familiares, escrever o projeto, fazer aulas, ter a bolsa aprovada, dialogar com minha orientadora e participar do grupo de pesquisas, vou a campo. Macaúbas é um município localizado no sul da Bahia. Em Janeiro de 2018, viajei até a capital baiana de avião com recursos próprios, onde fiquei na casa de uma prima que estuda na UFBA. De lá, comprei uma passagem de ônibus para Macaúbas com a reserva técnica da FAPESP. A viagem duraria cerca de dez horas. Por coincidência, ouvi na fila do ônibus um homem falando acerca do açude de Macaúbas e que a prefeitura havia decretado estado de calamidade devido à seca. Talvez por mais coincidência ainda, este mesmo homem sentou na poltrona ao lado da minha e conversamos ao longo de algumas horas sobre o assunto. $\mathrm{Na}$ época eu imaginei ser ali o ponto de partida da minha pesquisa etnográfica.

Em Macaúbas, me hospedei na casa de meus avós, na zona rural do município. Lá dividia meus afazeres entre arrumar o quarto onde eu estava, conversar diariamente com meus avós, a fim de obter informações e histórias acerca do açude e do ABC do açude, ir atrás de pessoas que poderiam ter outras histórias acerca da poesia e no final do dia tentava sistematizar as anotações de campo e escrever algumas páginas do relatório de pesquisa. Quando ia para a cidade, ficava hospedado na casa de uma tia, mas a rotina era praticamente igual. Registrava tudo com a ajuda de um gravador (também adquirido com dinheiro da reserva técnica) e com uma câmera, o que me ajudou também a transformar a pesquisa em meu TCC posteriormente.

Em Janeiro, fiquei em campo por aproximadamente 20 dias. Ao voltar para Carapicuíba, SP, onde moro, ao longo de quase um semestre fiquei elaborando e sistematizando tudo o que havia aprendido em campo, ora buscando mais referências, ora tirando dúvidas com minha orientadora. Além disso me desdobrava também nas aulas da graduação, quando por vezes vinham insights sobre a pesquisa. Tentei direcionar as escolhas das disciplinas que cursaria de acordo com meu tema de pesquisa, o que me ajudou também na escrita dos relatórios científicos e também dos trabalhos finais ou provas dessas disciplinas.

Voltei em Julho, dessa vez fui e voltei de São Paulo de ônibus (uma viagem de cerca de sessenta e oito horas, contando ida e volta). Nesse último campo fui até a casa de meus interlocutores para sanar algumas dúvidas que tinham me ocorrido durante a escrita do relatório para então finalizá-lo. 


\section{Etnografia, Antropologia e Ciências Sociais}

Em algum momento o estudante de ciências sociais ou antropologia se depara com a questão do método, da metodologia. Como é o caso de muitos dos programas oferecidos nessas áreas, há disciplinas específicas para tratar de questões de metodologia e, geralmente, a etnografia aparece enquanto tal. Se por um lado, Geertz, diz que podemos definir a antropologia "pelo que ela faz" e, "o que os praticantes fazem é etnografia” (1989, p.15), por outro lado, há a discussão levantada por Ingold, que defende que Antropologia não é etnografia (2017). Sem entrar no mérito dessa discussão, chamo aqui a atenção para algo que este último autor diz em relação a forma como é constituída uma "epistemologia que constrói o aluno como o mero receptor de conhecimento antropológico produzido em outros lugares - e não como um participante de sua contínua elaboração criativa" e que essa mesma epistemologia, que divide ensino e pesquisa, é a mesma que "constrói o nativo como um informante" (2017, p.346).

Geralmente, aqui no Brasil, os estudantes de ciências sociais têm que (ou são estimulados a) fazer um trabalho de conclusão de curso (TCC). Ao longo de sua jornada, no entanto, a sensação geral é que há uma divisão entre as disciplinas metodológicas e aquelas disciplinas acerca das bases teóricas e epistemológicas delas. Na prática, no fazer etnográfico, essa separação não acontece. É no momento da pesquisa que o estudante coloca em prática a articulação entre teoria e metodologia. Mas por que há essa separação na formatação do curso? A impressão que fica é que a ênfase das ciências sociais e da antropologia é numa história dessas disciplinas e pouco no fazer, em sua elaboração científica e criativa. Ora, se seguirmos o argumento de Ingold de que a antropologia (e as ciências sociais de modo geral) constitui um processo de atenção e de educação da percepção acerca dos acontecimentos da vida no mundo, talvez seja necessária uma reflexão sobre sua forma de educação, sobre a formação dos antropólogos e antropólogas e dos cientistas sociais.

Em conversas com alguns colegas de curso, a impressão é que muitos estudantes de ciências sociais (sobretudo aqueles que se interessam menos pela antropologia do que pela sociologia ou ciência política) pouco conhecem do trabalho 
dos antropólogos hoje - que podem variar desde uma pesquisa etnográfica com uma população indígena na Amazônia até uma igreja evangélica em São Paulo (Shiratori, 2019; Moraes Teixeira, 2012) - em parte devido ao caráter "historiográfico" das disciplinas obrigatórias em antropologia e em ciências sociais como um todo. Qual estudante de graduação nunca ficou embaraçado ao ser questionado com a pergunta (por vezes como forma de crítica) “o que faz um cientista social”?

De certa forma, prossegue Ingold, essa maneira de ensino da antropologia (nesse caso, mais que em sociologia ou ciência política), perde voz sobre debates sobre questões políticas e reflexões mais amplas acerca do mundo. Creio que este fato esteja mudando cada vez mais, dado o fato da catástrofe climática entrar na ordem do dia dos temas abordados pela antropologia, sobretudo devido a forma como os povos não ocidentais lidam com essa questão e são atingidos por ela. Mas, como um todo, o ofício de antropólogo é pouco publicizado para além das questões socioambientais.

A questão aqui não é negar a importância acerca da história das disciplinas e da contribuição dos autores para ela, mas questionar a maneira como acontece a formação dos cientistas sociais e antropólogos e antropólogas em sua contemporaneidade, para assim, enquanto estudantes poder contribuir de forma criativa para o "patrimônio" das disciplinas. É importante conhecer os autores, os clássicos e o que fizeram, igualmente importante aprender os métodos e teorias que constituem nossa disciplina, porém é também fundamental que todo esse conhecimento seja construído junto com os estudantes, que os momentos de "deslumbramento" de que fala Strathern ocorra como um aprendizado acerca dos conhecimentos antropológicos, para além de um voltar-se a si mesmo e as sucessões de revisões das maneiras de trabalhar da antropologia.

Ora, a etnografia pode nos ajudar a pensar formas de ocasionar esse deslumbramento. Mais que um método, a etnografia como uma "teoria de descrição", como diz Nader (2011), pode nos levar a outros lugares de reflexão e investigação. A importância de se conhecer a maneira como as pessoas fizeram essa teoria antes de nós, a meu ver, é despertar para formas criativas de lidar com as diferentes situações no que chamamos de campo. Se cada experiência é única, é o campo quem nos dita como devemos guiar nossa pesquisa. Isso é inclusive uma das coisas geralmente ensinadas hoje nos cursos acerca de metodologia de etnografia. 
Ironicamente, quando vamos a campo, aprendemos a desconfiar do método e a tomar cuidado com suas amarras. Ao mesmo tempo, dizer que não se precisa de método, sobretudo no atual contexto político, seria um tiro no pé. Aos poucos criamos formas de se estar no campo, alguns criam rotinas de pesquisa, temos que lidar com certos constrangimentos causados por possíveis objetos comuns em entrevistas, como gravadores e materiais audiovisuais. Muitas dessas coisas podemos aprender com os autores. Uma das grandes lições que Evans Pritchard aprendeu com Malinowski, por exemplo, foi “não seja um maldito idiota” (2005, p.243).

Poderíamos, por exemplo, falar como Feyrabend (2007) ao relatar como o método científico pode limitar as atividades dos próprios cientistas. Isso não descarta necessariamente a importância da Universidade no ensino, mas coloca uma questão crítica a sua forma de acontecer. Inclusive, se como defendo aqui, a etnografia pode ser uma forma de "pedagogia" para os estudantes de antropologia e ciências sociais, é preciso que a Universidade e o poder público contribuam para que isso aconteça, sobretudo com financiamento de pesquisa.

É muito comum muitos estudantes entrarem na universidade sem sequer saber o que é uma iniciação científica. Isso porque além do vestibular, existe uma outra barreira social que é o conhecimento acerca da vida acadêmica e da burocracia universitária. Políticas de fomento à pesquisa, como bolsas de iniciação científica são fundamentais sobretudo para a permanência dos estudantes na universidade. Sem verba para se manter na universidade (ainda que seja pública), muitos estudantes têm que trabalhar, estudar e ainda fazer o TCC, isso quando não ocorre a evasão.

Esse era meu caso quando ingressei na universidade. Foi a partir de uma conversa no ônibus com um professor que conheci o VISURB, grupo que faço parte até hoje, onde pude ter conhecimento de como aconteciam as pesquisas acadêmicas e, o mais importante, tive minha primeira bolsa de extensão universitária realizando alguns projetos do grupo, o que possibilitou me manter no curso e me dedicar às atividades que ali aconteciam. Mais que isso, também me possibilitou conhecer pessoas 
e fazer trocas com elas, por vezes trocas de amizade, cuidado e afeto, tão importantes para a vida acadêmica ${ }^{4}$.

Daí para a bolsa de iniciação científica foi um passo (largo $)^{5}$, e foi a partir da realização dessa pesquisa de IC que percebi um aumento muito grande no aproveitamento de todas as disciplinas em que eu cursava. Isso porque comecei a perceber de que forma poderia mobilizar tudo o que estava sendo transmitido em sala de aula de uma forma criativa e "concreta". Como comenta Goldman, "a característica fundamental da antropologia seria o estudo das experiências humanas a partir de uma experiência pessoal" (2006, p.167). Que podemos aprender com essas experiências? Bem, minha experiência como estudante da Universidade Federal de São Paulo, vindo de escola pública e realizando uma pesquisa de Iniciação Científica foi: se seu interesse está na pesquisa, encontre um grupo de pesquisa, um projeto de extensão ou mesmo um professor com projetos que mais se aproximem do que você se interessa.

\section{Educação da atenção}

Se, como dissemos, a educação em antropologia deve ser voltada para o treinamento da atenção e da percepção sobre o mundo, nada mais produtivo para isso do que realizar uma etnografia. A etnografia como teoria de descrição, como exercício de investigação e de como voltar a atenção para o mundo, transformando essa experiência pessoal em texto, em vídeo, em fotografias e até mesmo em desenhos. $\mathrm{Na}$ nossa disciplina, geralmente nossa ferramenta principal é o texto. O exercício da etnografia pode contribuir imensamente com essa produção textual também, dado contextos em que muitos estudantes começam a exercitar a escrita após entrar na

\footnotetext{
${ }^{4}$ Em Novembro de 2017, os estudantes do PPGAS/USP realizaram uma mesa no evento "Sexta do Mês" com o tema "Cuidados de si e condições de trabalho na academia", para debater, além de outras questões, as complicações psicológicas que uma lógica individualista de produtivismo acadêmico pode acarretar. $\mathrm{O}$ vídeo da mesa pode ser acessado em: <https://www.youtube.com/watch?v=WWt1wpaYlsU >

${ }^{5}$ É importante ressaltar também que na lógica de produtividade acadêmica, fazer iniciação científica é quase que obrigatório para ter uma boa colocação nos processos seletivos de pós-graduação. Fazer uma pesquisa durante a graduação foi fundamental para a construção de minha trajetória acadêmica e ingresso no mestrado, ainda que haja pessoas que ingressem na pós-graduação sem ter feito IC antes.
} 
universidade. E a escrita acadêmica, a escrita voltada para a pesquisa etnográfica é uma escrita muito particular.

Como comenta Strathern, “a escrita etnográfica cria um segundo campo” (2014, P.346) e, a relação entre o campo em si e o campo criado pela escrita é complexa pois, nenhum está em conformidade com o outro. Como tomar uma experiência tão particular e tão intensa, ou seja, uma experiência na vida e fazer caber em um texto? Como nossos autores e autoras fizeram tais coisas? Para além dos textos, fazendo etnografia podemos lançar luz sobre essas questões, ou seja, estando do lado de dentro da casa da construção do saber antropológico, e não olhando apenas pela janela. Será que talvez assim, os estudantes e a sociedade como um todo possam reconhecer o papel do trabalho dos antropólogos e antropólogas e a importância da produção de conhecimento antropológico ao lado de outras carreiras?

E o que podemos aprender com nossas pesquisas etnográficas? Algumas coisas são muito importantes, como, por exemplo, reler o que você já escreveu, o que nos leva a uma postura crítica daquilo que fizemos antes. Destaco também a importância da escolha do orientador ou orientadora e, na hora do TCC a importância de ter um parecerista para poder aprimorar o trabalho. Algo importantíssimo é dar o devido valor às descrições mais que às análises conceituais daquilo que experienciamos. $\mathrm{O}$ conhecimento etnográfico é produzido pela descrição, que não é menor que a análise, mas faz parte de seu processo (Ingold, 2017; Latour, 2012).

Ao chegar em campo, em Macaúbas, uma cidade familiar, comecei a pensar o quanto as relações intersubjetivas constituem nosso trabalho antropológico. Fazemos parte da experiência antropológica, sendo nossa ferramenta principal nossa percepção, enfim, nosso corpo presente em campo. Mas também foi importante perceber como a subjetividade em campo é importante para a pesquisa, além da pretensão de objetividade purista e cientificista. Não conseguiria realizar essa pesquisa se não fosse por minha história de vida. Ora, até mesmo Malinowski com sua pretensão de objetividade tinha um tanto importante de história de vida e subjetividade na realização de sua observação participante. Foi o fato de ser polonês e estudar na Inglaterra que o levou a estender seu trabalho de campo e a desenvolver um método científico que muitos consideram como marco inicial da etnografia. Como diz Nader (2011), hoje 
muitos ainda argumentam acerca da objetividade científica, mas isso geralmente não faz mais do que mascarar uma grande posição subjetiva do pesquisador ou pesquisadora.

O percurso que me levou a escrita deste artigo começa, portanto, mais que na prática de etnografia, na própria sala de aula. O momento em que escrevo, é aquele que fala Strathern, acerca do "segundo campo" da etnografia, que se estende no tempo. Muitos professores e professoras já fazem esse convite à etnografia como forma de aprendizado, assim como muitos grupos de pesquisa contribuem para tal formação. $\mathrm{O}$ que descrevo aqui é uma visão geral do curso de ciências sociais a partir da experiência particular de alguém que até recentemente era estudante de graduação. Por que nossa trajetória de vida e acadêmica aparece (quando aparece) por vezes tão apartada de nossas pesquisas? A importância disso reside no fato de se olhar de maneira crítica a forma como acontece nossa formação. Quando disse acima que pensei que o ponto de partida de minha etnografia foi aquele ônibus, numa conversa informal, foi porque não enxerguei mais longe, que na verdade ela havia começado ali, na sala de aula, em minha formação como pesquisador, enquanto estudante de ciências sociais. Ainda que num sentido mais prático o campo efetivamente só se inicie quando se está nele, ou em direção a ele, o argumento aqui reside no fato de que muitas vezes ensino e pesquisa são tidos como dois mundos distintos. O que perdemos com isso? Como argumenta Ingold, a antropologia demorou um século para que os chamados "nativos" acessassem a universidade, mas o diálogo com os alunos ainda tem um papel marginal na produção do conhecimento (Ingold, 2017). Reside aí também a importância tão atual de estar presente na sala de aula, em estabelecer trocas de conhecimento e de estar presente em corpo.

Se somos levados a ter uma postura de pesquisadores, mesmo dentre aqueles que miram na carreira docente, a educação em ciências sociais e antropologia deve se formatar a essas questões. A antropologia começa na sala de aula e não é apenas uma etapa a ser cumprida para posteriormente fora dela, no campo. Lemos muito acerca da etnografia como um processo, mas pouco falamos do papel da sala de aula, não nos vemos fazendo antropologia dentro dos muros da universidade. Para isso, uma educação pela pedra, pelo pé da calçada, pelo chão da fábrica, pelo terreiro, pelo sertão, pela aldeia, e também pela 
metrópole, pelos espaços da elite, nos laboratórios, nos ambientes digitais, mas também nas salas de aula. Para aprender da etnografia, frequentá-la.

\section{Como frequentá-1a em tempos de pandemia?}

Há uma questão de temporalidade sobre a pandemia que afeta a produção acadêmica de maneira particular. Continuamos produzindo. A palavra "webinar" veio à tona com a pandemia e ganhou uma vida social, substituindo os antigos "seminários" e temos uma proliferação de cursos online. Aproveito o momento para tratar apenas rapidamente da questão, pois muito do que escrevi acima tem de ser repensado nesse momento e provavelmente terá que ser revisto novamente em breve. No entanto, me parece oportuno ou mesmo incontornável tratar dessa questão já que tenho a oportunidade de revisitar esse texto que escrevi pouco antes do vírus chegar ao Brasil, antes de sua publicação. Três meses depois somos o segundo país com mais números de morte por covid-19, situação que se agrava à medida que se agrava a crise política.

Além de todo o contexto dos ataques neoliberais à educação como um todo, e às universidades públicas em particular ${ }^{6}$, temos agora também uma pandemia que traz à tona novas e velhas questões para as práticas de ensino e a pesquisa. No caso dos estudantes de ciências sociais e aqueles interessados em antropologia, muitas vezes a questão se coloca na impossibilidade de realizar os trabalhos de campo, e mais amplamente da subtração da experiência universitária, tão importante para essas duas práticas. Uma colega, recém ingressante do Programa de Pós-Graduação em Ciências Sociais da Unifesp, comentou em uma reunião do VISURB a falta que faz a experiência de vivenciar e construir corporal e coletivamente os espaços da universidade e como isso faz diferença para se articular politicamente nas questões da burocracia universitária, mas também como isso faz diferença nas trocas em aulas online.

Claro que há muitas possibilidades de se fazer ciências sociais em isolamento social. Na verdade, se trata de uma questão de responsabilidade para com nossos interlocutores, colegas de sala de aula e grupos de pesquisa, professores e funcionários

\footnotetext{
${ }^{6}$ Sobre o assunto, um trecho do Manifesto pelos rumos da universidade pública brasileira, redigido pelo Colegiado do curso História - Memória e Imagem, da Universidade Federal do Paraná: https://n1edicoes.org/090. Acesso em 27/06/2020
} 
das universidades. Mas faremos isso por uma questão de responsabilidade e pensando coletivamente uma saída pela ética do cuidado (conosco e com os outros entes humanos e outros-que-humanos a nossa volta) ou estaremos apenas seguindo a velha conhecida lógica liberal do produtivismo acadêmico? Com movimentos de aceleração e desaceleração, muitas questões colocadas nas linhas acima podem parecer obsoletas, mas a questão sempre atual é acerca da forma como fazemos conhecimento e a experiência universitária.

\section{Referências}

EVANS-PRITCHARD, Edward. "Algumas reminiscências e reflexões sobre o trabalho de campo.” In: Bruxaria, oráculos e magia entre os Azande. Rio de Janeiro: Zahar, 2005, p. 243-255.

FEYRABEND, Paul. Contra o método. São Paulo: Editora Unesp, 2007.

FIGUEIREDO, Felipe «ABC do Açude: Percepção, Imaginário e Memória no sertão», Ponto Urbe [Online], 23|2018, posto online no dia 28 dezembro 2018, consultado o 27 junho 2020.URL: http://journals.openedition.org/pontour be/5732;

GEERTZ, Clifford. A interpretação das culturas. Rio de Janeiro: LTC, 1989.

GOLDMAN, Márcio. "Alteridade e Experiência: Antropologia e Teoria Etnográfica”. Etnográfica, v. 10, n. 1, Lisboa, maio 2006.

LATOUR, Bruno. Reagregando o social: uma introdução à teoria do Ator-Rede. Salvador: Edufba, 2012; Bauru, SP: Edusc, 2012.

LÉVI-STRAUSS, Claude. "Lugar da Antropologia nas Ciências Sociais e problemas levantados por seu ensino". In.: Antropologia Estrutural I, São Paulo: Cosac Naify, 2012.

INGOLD, Tim. "Antropologia não é etnografia”. In:__. Estar vivo: ensaios sobre movimento, conhecimento e descrição. Petrópolis, RJ: Vozes, 2017, p. 122-146

MALINOWSKI, Bronislaw. "Tema, método e objetivo de pesquisa". In.: Argonautas do Pacífico Ocidental. [Coleção “Os pensadores"], São Paulo: Editora Abril, 1998.

MORAES TEIXEIRA, Jacqueline. Corpo e Sexualidade: Os Direitos Reprodutivos na Igreja Universal do Reino de Deus. Revista Mandrágora, v. 18, p. 53-80, 2012.

NADER, Laura. "Ethnography as theory". HAU: Journal of Ethnographic Theory 1 (1): 211-219, 2011.

SHIRATORI, Karen. O olhar envenenado: a perspectiva das plantas e o xamanismo vegetal jamamadi (médio 
Purus, AM).Mana, Rio de Janeiro, v. 25,n. 1,p. 159-188

STRATHERN, Marilyn. O Efeito Etnográfico. São Paulo: Cosac Naify, 2014. 